\title{
The selective treatment of clinical mastitis based on on-farm culture results: I. Effects on antibiotic use, milk withholding time, and short-term clinical and bacteriological outcomes
}

\author{
A. Lago, ${ }^{1}$ S. M. Godden, ${ }^{*}$ R. Bey, ${ }^{*}$ P. L. Ruegg,, and K. Leslieł \\ ${ }^{*}$ Department of Veterinary Population Medicine, College of Veterinary Medicine, University of Minnesota, Saint Paul 55108 \\ †Department of Dairy Science, College of Agriculture and Life Sciences, University of Wisconsin, Madison 53706 \\ ¥Department of Population Medicine, Ontario Veterinary College, University of Guelph, Ontario, Canada N1G 2W1
}

\begin{abstract}
The objective of this multi-state, multi-herd clinical trial was to evaluate the efficacy of using an on-farm culture system to guide strategic treatment decisions in cows with clinical mastitis. The study was conducted in 8 commercial dairy farms ranging in size from 144 to 1,795 cows from Minnesota, Wisconsin, and Ontario, Canada. A total of 422 cows affected with mild or moderate clinical mastitis in 449 quarters were randomly assigned to either (1) a positive-control treatment program or (2) an on-farm, culture-based treatment program. Quarter cases assigned to the positive-control group received immediate on-label intramammary treatment with cephapirin sodium. Quarters assigned to the culture-based treatment program were cultured on-farm and treated with cephapirin sodium after 18 to $24 \mathrm{~h}$ of incubation if they had gram-positive growth or a mixed infection. Quarters with gram-negative or no growth did not receive intramammary therapy. The proportion of quarter cases assigned to positive-control and culture-based treatments that received intramammary antibiotic therapy because of study assignment was 100 and 44\%, respectively; the proportion of cases that received secondary antibiotic therapy was 36 and $19 \%$, respectively; and the proportion of cases that received intramammary antibiotic therapy because of study assignment or secondary therapy was 100 and $51 \%$, respectively. A tendency existed for a decrease in the number of days in which milk was discarded from cows assigned to the culture-based treatment program versus cows assigned to the positive-control group (5.9 vs. $5.2 \mathrm{~d}$ ). No statistically significant differences existed between cases assigned to the positive-control and cases assigned to the culture-based treatment program in days to clinical cure (2.7 vs. $3.2 \mathrm{~d}$ ), bacteriological cure risk within $21 \mathrm{~d}$ of enrollment (71 vs. 60\%), new intra-
\end{abstract}

Received November 27, 2010.

Accepted May 23, 2011.

${ }^{1}$ Corresponding author: alfonso.lago@gmail.com mammary infection risk within $21 \mathrm{~d}$ of enrollment (50 vs. $50 \%$ ), and treatment failure risk (presence of infection, secondary treatment, clinical mastitis recurrence, or removal from herd within $21 \mathrm{~d}$ after enrollment; 81 vs. $78 \%$ ). In summary, the use of an on-farm culture system to guide the strategic treatment of clinical mastitis reduced intramammary antibiotic use by half and tended to decrease milk withholding time by $1 \mathrm{~d}$, without significant differences in days to clinical cure, bacteriological cure risk, new intramammary infection risk, and treatment failure risk within $21 \mathrm{~d}$ after the clinical mastitis event.

Key words: clinical mastitis, selective treatment, onfarm culture, bi-plate

\section{INTRODUCTION}

Mastitis has been recognized as the most frequent reason for antibiotic use in dairy cattle (Sundlof et al., 1995; Mitchell et al., 1998). In a recent study in 20 Wisconsin conventional dairies, $80 \%$ of all antimicrobial drugs used were used for treatment or prevention of mastitis (Pol and Ruegg, 2007). Interestingly, 50\% of all antimicrobial drugs used were solely for treatment of clinical mastitis. Problems attributed to the use of antibiotics in animals include those of antibiotic residues and the potential for development of antibiotic resistance (Owens et al., 1997; Barton, 2000; Sol et al., 2000; Erskine et al., 2002; Makovec and Ruegg, 2003; Pitkälä et al., 2004; Pol and Ruegg, 2007).

Another concern is that the value of discarded milk following antibiotic treatment can exceed $\$ 100$ per cow in the herd per year (Bartlett et al., 1991). Thus, increased awareness exists among producers and veterinarians of treatment-related costs and the economic costs of extensive antibacterial therapy for mastitis (Erskine et al., 2003). However, contrary to the expected decrease in discarded milk in a non-antibiotic treatment regimen, a clinical trial evaluating 2 antibiotic treatment regimens and 1 based just on the administration of oxytocin found that the cost of treatment, calculated 
by adding the cost of the therapy to the value of the milk withheld, did not differ between 1 of the antibiotic treatments and the non-antibiotic regimen. The oxytocin treatment costs were not significantly lower than for amoxicillin because of the increased number of milkings required for some of the affected quarters of the oxytocin-treated group to produce milk with a normal appearance (Van Eenennaam et al., 1995).

It has been reported that 10 to $40 \%$ of cultures from clinical mastitis cases yield no bacterial growth, and so do not require antimicrobial therapy (Roberson, 2003). Another $40 \%$ of positive cultures (gram-negatives, yeast) are not susceptible to most approved intramammary antimicrobial drugs. Also, a large proportion of gram-negative infections are quickly cleared by the cow's own immune system (although occasional persistence of gram-negative infections occurs; Erskine et al., 1992; Pyörälä et al., 1994). Conversely, intramammary antibiotic therapy is routinely recommended for infections caused by gram-positive organisms such as Staphylococcus aureus, Streptococcus agalactiae, and environmental streptococci species. Based on these numbers, Roberson (2003) estimated that antibiotics labeled for intramammary use would not be justified for 50 to $80 \%$ of clinical mastitis cases.

Consequently, clinical mastitis treatment decisions should be based on culture results. However, laboratory culture has not been routinely used by many dairies because of the time delay between submission of milk samples and reporting of results. Adoption of rapid on-farm milk culture systems would allow producers to make strategic treatment decisions for clinical mastitis cases, based on knowing the pathogen involved. The Minnesota Easy Culture System (University of Minnesota, Saint Paul), a commercial on-farm milk culture system, offers 2 different types of selective culture media systems. The bi-plate system is a plate with 2 different types of agar: MacConkey agar on one half selectively grows gram-negative bacteria, whereas Factor agar, similar to KLMB agar (Beatty et al., 1985), on the other half of the plate, selectively grows gram-positive organisms while inhibiting the growth of gram-negative bacteria with antibiotics (University of Minnesota, St. Paul). Alternately, the tri-plate system is a plate with 3 different types of agar. In addition to including MacConkey agar and Factor agar, it also includes a section of MTKT agar, which is selective for streptococci. The bi-plate culture system results, in agreement beyond chance with laboratory results, test characteristics, and predictive values for identification of gram-positive bacterial growth (vs. no growth and gram-negative growth), were described elsewhere (Lago, 2009). Kappa values of $61 \%$, sensitivity of $78 \%$, specificity of $83 \%$, predictive value of a positive result of $74 \%$, and predictive value of a negative result of $86 \%$ were obtained when the bi-plate was used on-farm to culture quarter secretion samples from clinical mastitis cases. The authors concluded that the Minnesota Easy Culture Bi-Plate System is a useful cow-side test to correctly identify gram-positive bacterial growth in quarter secretion samples from clinical mastitis cases. The use of on-farm milk culture for the selective treatment of clinical mastitis may represent a tremendous opportunity to decrease antimicrobial use on commercial dairy farms without sacrificing the efficacy of treatment or the long-term health and production potential of the cow. Benefits could include decreased economic cost of therapy, decreased risk of antimicrobial residues in milk, and a decrease in the potential risk for development of antimicrobial resistance in mastitis pathogens. However, many of these potential benefits need further evaluation to confirm and quantify the nature of these proposed benefits.

The objective of this study was to investigate the efficacy of using an on-farm milk culture system to guide strategic treatment decisions in cows with mild and moderate clinical mastitis. Outcomes evaluated included (1) risk of receiving primary intramammary antibiotic therapy because of study assignment, (2) risk of receiving secondary (or extended) intramammary antibiotic therapy, (3) days to return to visibly normal milk (days to clinical cure), (4) days of milk withheld from market (days out of the tank), (5) bacteriological cure risk within $21 \mathrm{~d}$ of enrollment, (6) new IMI risk within $21 \mathrm{~d}$ of enrollment, and (7) treatment failure risk (presence of infection, secondary treatment, clinical mastitis recurrence, or removal from herd within 21 d of enrollment).

\section{MATERIALS AND METHODS}

\section{Study Design}

A randomized controlled clinical trial was conducted between June 2005 and April 2007 in 8 dairy herds. In each herd, cows were enrolled in the study during a period not longer than 6 mo. These herds (2 in Minnesota, 5 in Wisconsin, and 1 in Ontario, Canada), were a convenience sample of commercial dairy farms from the North American Great Lakes Region (Table 1). Herd size ranged from 144 to 1,795 cows, averaging 920 cows. Seven of the herds were housed in freestalls and 1 in a tie-stall housing system. Annual milk production among those herds ranged from $9,545 \mathrm{~kg}$ to 12,818 $\mathrm{kg}$, averaging $11,123 \mathrm{~kg}$. Bulk tank milk SCC ranged from 182,000 cells $/ \mathrm{mL}$ to 535,000 cells $/ \mathrm{mL}$, averaging 282,500 cells $/ \mathrm{mL}$. Selected producers were required to maintain compliance with the study protocols and 
Table 1. Herd descriptors, as well as etiology of infection and herd contribution for clinical mastitis cases enrolled in the study

\begin{tabular}{|c|c|c|c|c|c|c|c|c|}
\hline Item & Herd A & Herd B & Herd C & Herd D & Herd E & Herd F & Herd G & Herd $\mathrm{H}$ \\
\hline Housing type & Freestall & Freestall & Freestall & Freestall & Freestall & Freestall & Freestall & Tie Stall \\
\hline Stall base & Mattress & Mattress & Deep bed & Deep bed & Mattress & Mattress & Deep bed & Mattress \\
\hline Size (cows) & 1,001 & 299 & 197 & 1,602 & 1,795 & 568 & 1,754 & 144 \\
\hline $\mathrm{RHA}^{\mathrm{l}}(\mathrm{kg})^{\prime}$ & 10,500 & 10,227 & 12,818 & 12,318 & 9,591 & 12,425 & 11,563 & 9,545 \\
\hline $\mathrm{SCC}^{2}$ (cells $\left./ \mathrm{mL}\right)$ & 261,000 & 296,000 & 192,000 & 334,000 & 182,000 & 223,000 & 535,000 & 237,000 \\
\hline Gram-negatives & 15 & 17 & 19 & 39 & 34 & 67 & 43 & 3 \\
\hline Gram-positives & 35 & 53 & 44 & 38 & 26 & 11 & 24 & 63 \\
\hline Mixed infection & 3 & 2 & 6 & 0 & 5 & 0 & 9 & 1 \\
\hline Study contribution ${ }^{4}$ & 28 & 14 & 4 & 12 & 27 & 4 & 5 & 6 \\
\hline
\end{tabular}

${ }^{1}$ Milk production annual rolling herd average (RHA).

${ }^{2}$ Bulk tank milk SCC.

${ }^{3}$ Etiological classification was based on laboratory culture results.

${ }^{4}$ Number of cases of clinical mastitis enrolled in this herd/number of cases of clinical mastitis enrolled in the study.

record keeping; have trained personnel, individual animal identification, treatment facilities, appropriate drug storage capabilities, and refrigeration and freezer capacity; participate in a DHIA testing program; and demonstrate sufficient interest in the study. On-farm culturing was done by the herdsman or other dairy employee who was trained in the study protocols, on-farm culturing procedures, and record keeping before the initiation of the study. Four of the 8 dairies participating in the study were already implementing on-farm culture before the initiation of the study.

\section{Case Definition}

Clinical mastitis was diagnosed by herd personnel if milk from 1 or more quarters was abnormal in color, viscosity, or consistency, with or without accompanying heat, pain, redness, or swelling of the quarter, or generalized illness. All lactating cows in the herd were eligible for enrollment at the time of clinical mastitis occurrence when only the milk was abnormal (mild or grade 1 clinical mastitis) or when the milk and the quarter were affected (moderate or grade 2 clinical mastitis). Cows exhibiting severe or grade 3 clinical mastitis (depression, anorexia, dehydration, fever) or any cow with fewer than 3 functional quarters were ineligible for enrollment.

\section{Enrollment Process}

Cows with clinical mastitis were detected in the milking parlor by the milkers upon observation of clinical signs of mastitis (e.g., visibly abnormal milk or quarter). If the cow met the designated inclusion criteria for enrollment, herd personnel aseptically collected a single milk sample from the affected quarter. For a first clinical mastitis episode (cow not previously enrolled in the study), eligible cows for enrollment were randomly assigned following a simple randomization schedule to either the positive-control group or culture-based treatment group by opening a pre-identified sealed opaque envelope following a sequential order. If more than 1 quarter was affected, all affected quarters were assigned to the same treatment group. For a second (or greater) clinical mastitis episode in the same cow (i.e., cow had been previously enrolled) in the same or in a different quarter, the quarter was assigned to the same treatment group as was previously assigned.

\section{Treatment Groups}

Positive-Control Group. Immediately after enrollment, the quarter milk sample that had been aseptically collected was frozen on-farm at $-20^{\circ} \mathrm{C}$ and the affected quarter(s) were infused with 1 syringe (200 mg) of cephapirin sodium (Cefa-Lak; Fort Dodge Animal Health Inc., Fort Dodge, IA). The treatment was repeated once, $12 \mathrm{~h}$ after the first treatment, according to label directions. A milk-withdrawal period of $96 \mathrm{~h}$ and a slaughter-withdrawal period of $4 \mathrm{~d}$ were followed after the last treatment.

Culture-Based Treatment Group. The aseptically collected milk sample(s) from the affected quarter(s) was first cultured on-farm by trained herd personnel using the Minnesota Easy Culture System (University of Minnesota, St. Paul). This on-farm milk culture system consists of a bi-plate, which is a Petri dish with 2 different types of agar: MacConkey agar on one half that selectively grows gram-negative bacteria and Factor media on the other half of the plate that selectively 
grows gram-positive bacteria. A sterile cotton swab was dipped into the milk sample and then plated onto the Factor media half of the bi-plate, redipped into the milk, and then applied to the MacConkey media half of the bi-plate. The plate was placed in an on-farm incubator and incubated at approximately $37^{\circ} \mathrm{C}$ for 18 to 24 h. After inoculation of the swabbed media, the quarter milk sample was frozen on-farm at $-20^{\circ} \mathrm{C}$. The next day, the plate was examined for bacterial growth and interpreted by herd personnel according to guidelines provided by the Minnesota Easy Culture System II user's manual (University of Minnesota Laboratory for Udder Health, 2004). If bacteria did not grow, the plate was returned to the incubator and re-read approximately 18 to $24 \mathrm{~h}$ later. Final results for each sample plate were recorded as (1) gram-positive, when bacteria grew only in the Factor agar media of the bi-plate; (2) gram-negative, when bacteria grew only in the MacConkey agar media of the bi-plate; (3) no growth, when bacteria did not grow on either media; or (4) mixed infection when bacteria grew on both media. The decision regarding initiation of intramammary antibiotic therapy the day after enrollment of the clinical mastitis case was based on the on-farm culture results. Quarters from which gram-positive bacteria were isolated or had a mixed infection received the same intramammary antibiotic treatment following the same procedures as cases assigned to positive-control treatment. If the on-farm milk culture result was gram-negative or no growth, the quarter did not receive intramammary therapy.

After enrollment, farm personnel recorded short-term outcomes, including the number of days the cow was treated, the number of days to return to visibly normal milk, number of days out of tank, and whether or not extended (secondary) therapy was given. Study technicians visited the study herds once per week and aseptically collected single-quarter milk samples from enrolled quarters at approximately $14 \mathrm{~d}$ post-enrollment (10-16 $\mathrm{d}$ post-enrollment) and $21 \mathrm{~d}$ post-enrollment (17-23 d post-enrollment). All milk samples were transported on ice to the regional mastitis culture laboratory (St. Paul, MN; Madison, WI; or Guelph, ON, Canada) and frozen at $-20^{\circ} \mathrm{C}$ until bacteriological culture was completed. In addition, study technicians observed herd personnel performing on-farm culture procedures, recorded incubator temperature and evaluated the incubator humidity conditions, and revised the bi-plate colony growth readings done by farm personnel during the previous week (used bi-plates were kept in the refrigerator by farm personnel until technicians visited the farm once per week).

\section{Laboratory Bacteriological Culture}

Aerobic culture methodologies for frozen milk samples (enrollment d 0, 14, and 21) collected on farms were standardized among laboratories at all 3 participating sites and performed in accordance with the National Mastitis Council guidelines (NMC, 1999). Briefly, individual quarter milk samples were thawed at room temperature. While still cold, $0.01 \mathrm{~mL}$ of milk was plated onto MacConkey agar plates and Factor agar plates using sterile calibrated loops. Inoculated plates were incubated at $37^{\circ} \mathrm{C}$. After incubation for 18 to $24 \mathrm{~h}$, all plates were observed for microbial growth. Those plates having growth were recorded and species identification was started. All plates were placed in the incubator for an additional 18 to $24 \mathrm{~h}$ and reevaluated for microbial growth. Colonies on MacConkey agar plates were presumptively identified based on colony morphology. Colony color was used as a means of determining if the organism on the plate was a lactosefermenting organism. Isolates were also Gram stained to assist in organism identification. Organism identity was confirmed using the API 20E test (bioMérieux Vitek Inc., Hazelwood, MO). Colonies suspected as being staphylococci, based on colony morphology, were confirmed as staphylococci, based on catalase reaction and microscopic morphology. Organisms suspected of being Staph. aureus were confirmed using the tube coagulase reaction. Those organisms that were catalase positive and coagulase negative were classified as Staphylococcus spp. Catalase-negative streptococci were streaked onto an MTKT agar plate, which is selective for Streptococcus spp. only, to determine the esculin reaction and presumptive identification before organism confirmation using the API Streptococcus identification system (bioMérieux Vitek Inc.).

\section{Data Analysis-Definition of Outcome Variables}

Risk of Receiving Primary Intramammary Antibiotic Therapy Because of Study Assignment. All clinical mastitis cases assigned to positivecontrol treatment were treated with 2 infusion syringes (200 mg) of cephapirin sodium (Cefa-Lak; Fort Dodge Animal Health Inc.). However, for cases assigned to the culture-based treatment group, only quarters from which gram-positive bacteria were isolated or had a mixed infection initially received antibiotic treatment.

Risk of Receiving Secondary Intramammary Antibiotic Therapy Because of Non-Responsive Cases. Secondary (or extended) treatment was allowed in cases that did not respond to the initial treatment regimen assigned. Failure to respond was defined as (1) increasing severity (i.e., became grade 3 ) of the clinical mastitis case within 24 to $48 \mathrm{~h}$ after the initial treatment regimen was implemented (either intramammary antibiotic treatment or no treatment), or (2) failure to decrease in severity (grade) of mastitis when assessed 
by herd personnel approximately $48 \mathrm{~h}$ after the initial treatment regimen was implemented.

Risk of Receiving Intramammary Antibiotics Because of Primary or Secondary Therapy. The overall risk of receiving intramammary antibiotic treatment was represented by a dichotomous outcome denoting no administration (0) or administration (1) of intramammary antibiotic therapy because of either study assignment or secondary treatment for each quarter case of mastitis.

Days to Clinical Cure and Days Out of the Tank. Herd personnel assessed mammary gland secretion daily after enrollment, and recorded the date and time when milk had returned to being visibly normal (no clots, no flakes). The date and time when milk was first marketed after enrollment of the clinical mastitis case was also recorded by herd personnel.

Bacteriological Cure Risk. A quarter was considered infected when 1 or 2 bacterial species were isolated from a quarter milk sample. The isolation of 2 bacterial species was considered a mixed infection. A quarter sample was considered contaminated if 3 or more bacterial species were isolated. A bacteriological cure within a quarter was defined as the presence of 1 or 2 microorganisms in the enrollment milk sample, and the absence of the same specified microorganism(s) in both d-14 and -21 milk samples.

New IMI Risk. A quarter was considered newly infected whenever a new bacterial species that was not previously present in the enrollment sample (d 0) was isolated from quarter milk samples collected either at d 14 or 21 after enrollment. Contaminated samples at enrollment or new bacteria isolated from contaminated samples collected at any of the 2 sampling times after enrollment were not included in this calculation.

Treatment Failure Risk. It was considered a treatment failure if 1 or 2 bacterial species were isolated from quarter milk samples collected either at d 14 or 21 after enrollment, if secondary treatment was administered, if the quarter experienced a clinical mastitis recurrence within $21 \mathrm{~d}$ after enrollment (clinical mastitis recurrence was defined as detection of a new clinical mastitis case in the same quarter at least $14 \mathrm{~d}$ after the enrollment of the previous case of clinical mastitis), or if the cow was removed from the herd because of culling or death within $21 \mathrm{~d}$ after enrollment. Treatment failure was described as a dichotomous outcome. A treatment failure value of 1 indicates that any one of the previously mentioned conditions occurred. A treatment failure value of 0 indicates that none of the conditions occurred. Analysis of the treatment failure risk was done in an attempt to eliminate potential omission bias created by not including, in the bacteriological cure analysis, cases where no bacteria were isolated from the enrollment sample, and cases without a follow-up culture result because of clinical mastitis recurrence or because the cow was removed from the herd. In addition, the treatment failure outcome eliminates the potential confounding induced by secondary treatments or treatment of recurrent cases of clinical mastitis.

\section{Statistical Analysis_Models and Modeling Strategy}

Database summaries and plots were used for exploratory data analysis. Basic diagnostic techniques were used to evaluate normality, independence, homoscedasticity, collinearity, and linearity of variables.

Generalized Linear Mixed Models for Dichotomous Outcome Variables. Binary response variables, such as risk for secondary intramammary antibiotic therapy, risk of receiving intramammary antibiotic therapy because of study assignment or secondary treatment, quarter risk for a bacteriological cure, quarter risk for a new IMI, and quarter risk for treatment failure, were modeled as a function of treatment group and other covariates using logistic multivariable regression. The treatment effect on the risk for the listed outcome variables following the clinical mastitis case was analyzed by generalized linear mixed models using the GLIMMIX PROC of SAS version 9.1 (SAS Institute, 2003) with herd and cow included as random effects to account for the clustering of cows within herds, and of quarters within cows. This was done by specifying a random statement in the model (random herd cow). The generalized linear mixed models were specified as $\operatorname{logit}\left(Y_{i j k}\right)=\alpha+\boldsymbol{\beta}_{1 \mathbf{i j}}^{\prime} \mathbf{X}_{1 \mathbf{i j}}+\boldsymbol{\beta}_{2 \mathbf{j}}^{\prime} \mathbf{X}_{2 \mathbf{j}}+v_{i}+u_{j k}$, where the subscripts $i, k$, and $j$ denote the $i$ th quarter, the $j$ th cow, and the $k$ th herd; $Y_{i j k}=$ the fitted probability from the $i$ th quarter, the $j$ th cow, and the $k$ th herd; $\alpha=$ regression intercept; $\mathbf{X}_{1 \mathrm{ij}}=$ vector of covariates associated with quarter $i$ of cow $j ; \boldsymbol{\beta}_{1 \mathrm{ij}}^{\prime}=$ vector of coefficients for $\mathbf{X}_{1 \mathrm{ij}} ; \mathbf{X}_{2 \mathbf{j}}=$ vector of cow-level exposures for cow $j ; \beta_{2 \mathrm{j}}^{\prime}$ $=$ vector of coefficients for $\mathbf{X}_{2 \mathrm{j}} ; v_{i}=$ residual variation between quarters; and $u_{j k}=$ random effect reflecting clustering of quarters within cows and of cows within herds.

Covariates such as cow parity, DIM at the clinical mastitis event, previous occurrence of a clinical mastitis case in the same quarter in the present lactation, number of quarters affected with clinical mastitis in the same cow at enrollment, case severity, and etiology of infection were included in the model if it was a potential confounding variable. To determine if a covariate confounded the treatment effect on the outcome, the crude estimate of treatment group (positive control- vs. culture-based treatment) was compared with the adjusted estimate for that third variable. It 
was concluded that the variable confounded the association between treatment group and outcome variable if the ratio between the difference of the crude estimate and the adjusted estimate versus the crude estimate was greater than $10 \%$. Each variable was examined for potential confounding 1 at a time by regression. Once the confounder variables were identified, the next step was to place all confounders into a full model with 2-way interaction terms between treatment and the confounder. To simplify the model, each nonsignificant interaction term was removed 1 at a time using a backward stepwise approach, starting with the least significant interaction term and running the model again until no nonsignificant interaction terms existed in the model. With nonsignificant interaction terms removed from the model, it was determined whether covariates existed in the model that were not in an interaction term that might be a confounder. The least significant term was removed and it was evaluated to determine if this affected the treatment effect estimate, with the goal being to assess whether the variable confounded the treatment-outcome relationship. If the variable was an important confounder, it was returned to the model and other variables were assessed 1 at a time to see if they were confounders. The treatment variable was forced in the model. Once all nonsignificant interaction terms were removed, as well as covariates that did not confound the exposure-outcome relationship, this was the final model. Final significance was declared at $P$ $<0.05$.

Time-to-Event Models. Binary responses with a time-to-event component, such as days to clinical cure and days out of the tank, were modeled using survival analysis. The Cox proportional hazards regression method was used to test the logistic analysis explanatory variables (see previously described covariates) simultaneously for their association with time until event (PROC TPHREG). The Cox model assumes a proportional hazard constant over time. This assumption was examined by the log-cumulative hazard plot to check if the lines for both treatment groups were parallel, and tested by modeling an interaction between cohort and the follow-up time. The clustering of cows within herd was considered by specifying the Covsandwich (aggregate) option in the procedure statement and then specifying herd as the level of aggregate (id = herd). The Covsandwich option requests a robust sandwich estimate for the covariance matrix, which results in a robust standard error for the parameter estimates. The survival function was modeled as $\lambda_{j}=\lambda_{0} * \exp \left(\beta x^{\prime}\right)$, where $\lambda_{j}=$ hazard function (risk of the event of interest in cow $j$ at time $t$, where $t$ is the follow-up time); $\lambda_{0}$ $=$ baseline hazard; $\beta x^{\prime}=$ linear predictor containing a vector of covariates $x$, with regression coefficients $\beta$.
For days to clinical cure and days out of the tank, cows were censored when the cow was removed from the herd immediately after the clinical mastitis event or when further follow-up data was not available. The assumption of independent censoring between both treatment groups was assessed by comparing the proportion of censored cows between both treatment groups. In addition, a sensitivity analysis looking at situations of complete positive correlation (every cow censored experienced the event of interest) or negative correlation (censored cows did not experienced the event of interest) between censoring and the event of interest was done. If the violation of this assumption did not dramatically alter the treatment effect estimate $(<10 \%)$, it was concluded that censoring did not introduce bias.

\section{RESULTS}

\section{Descriptive Data}

A total of 422 cows affected with clinical mastitis in 449 quarters were enrolled in the study. Of those, 214 cows with 229 affected quarters were assigned to positive-control treatment, and 208 cows with 220 affected quarters were assigned to culture-based treatment. Cow- and quarter-level descriptors and etiology of infection at enrollment for both study groups are shown in Table 2 . The severity distribution of the clinical cases enrolled in the study was $68 \%$ for mild cases and $32 \%$ for moderate cases. Cows with severe cases of mastitis were not eligible for enrollment in this study. The parity distribution of the cows at the time of the clinical mastitis event was 33, 30, and $37 \%$ for first-, second-, and third-or-greater-parity cows, respectively. The mean and median DIM to the occurrence of a clinical mastitis case were 170 and $150 \mathrm{~d}$, respectively. Cows could have 1 or more quarters affected with clinical mastitis when enrolled in the study. Ninety percent of the cows had just 1 quarter affected and the remaining $10 \%$ of cows had 2 or more quarters affected.

Bacteria were isolated from $66 \%$ of quarters with clinical mastitis at enrollment. Coliform bacteria were the most commonly isolated pathogen (24\% of clinical mastitis cases), followed by non-agalactiae streptococci (14\% of clinical mastitis cases), CNS (9\% of clinical mastitis cases), Staph. aureus (7\% of clinical mastitis cases), and other infections (7\% of clinical mastitis cases). Among coliforms, bacteria such as Escherichia coli, Klebsiella spp., and Enterobacter spp. represented 18, 5, and $1 \%$ of all cases, respectively. Other gram-negative bacteria such as Pantoea spp., Pseudomonas spp., and Salmonella spp. each represented less than $1 \%$ of all cases. Streptococcus agalactiae was not isolated from any of the clinical mastitis cases. The non-agalactiae 
Table 2. Cow and quarter level clinical mastitis case descriptors and etiology of infection at enrollment for both study groups

\begin{tabular}{|c|c|c|c|c|}
\hline Item & \multicolumn{2}{|c|}{ Positive-control group } & \multicolumn{2}{|c|}{ Culture-based group } \\
\hline \multicolumn{5}{|l|}{ Sample size } \\
\hline Number of cows enrolled & 214 & - & 208 & - \\
\hline \multicolumn{5}{|l|}{ Severity_quarter level } \\
\hline Mild (first grade) & $63(145 / 229)$ & $10-95$ & $72(159 / 220)$ & $20-100$ \\
\hline First & $34(73 / 214)$ & $0-57$ & $32(67 / 208)$ & $10-57$ \\
\hline Second & $33(71 / 214)$ & $17-50$ & $26(54 / 208)$ & $22-50$ \\
\hline Third+ & $33(70 / 214)$ & $13-83$ & $42(87 / 208)$ & $14-75$ \\
\hline \multicolumn{5}{|l|}{ DIM-cow level } \\
\hline Mean & $174(214)$ & $125-224$ & $166(208)$ & 119-195 \\
\hline Median & $155(214)$ & $117-221$ & $143(208)$ & $56-238$ \\
\hline \multicolumn{5}{|l|}{ Quarters affected-cow level } \\
\hline \multicolumn{5}{|l|}{ Etiology ${ }^{3}$ - quarter level } \\
\hline No growth & $32(71 / 222)$ & $23-42$ & $34(74 / 216)$ & $10-52$ \\
\hline Gram-negatives & $27(60 / 222)$ & $0-44$ & $23(50 / 216)$ & $0-80$ \\
\hline Escherichia coli & $20(44 / 222)$ & $0-67$ & $16(34 / 216)$ & $0-41$ \\
\hline Klebsiella spp. & $5(10 / 222)$ & $0-10$ & $6(13 / 216)$ & $0-66$ \\
\hline Gram-positives & $31(69 / 222)$ & $11-63$ & $37(80 / 216)$ & $10-63$ \\
\hline Non-agalactiae streptococci & $11(25 / 222)$ & $6-24$ & $15(32 / 216)$ & $9-38$ \\
\hline Staphylococcus spp. & $7(16 / 222)$ & $0-13$ & $10(22 / 216)$ & $0-14$ \\
\hline Staphylococcus aureus & $6(13 / 222)$ & $0-31$ & $8(17 / 216)$ & $0-38$ \\
\hline Bacillus spp. & $5(11 / 222)$ & $0-27$ & $3(6 / 216)$ & $0-20$ \\
\hline Other & $9(21 / 222)$ & $0-20$ & $4(8 / 216)$ & $0-13$ \\
\hline Mixed infection/contaminated & $<1(1 / 222)$ & $0-22$ & $2(4 / 216)$ & $0-15$ \\
\hline
\end{tabular}

${ }^{1}$ Cow and quarter-level descriptors [\% (n)]. The fraction numerator was the number of quarters or cows in each category and the denominator was the number of quarters or cows enrolled (or from which data were available).

${ }^{2}$ Herd range for the different descriptors [minimum herd (\%)-maximum herd (\%)].

${ }^{3}$ Etiological classification was based on laboratory culture results.

streptococci, Streptococcus dysgalactiae, Streptococcus uberis, Enterococcus spp., and Aerococcus spp. represented $5,2,4$, and $1 \%$ of all cases, respectively. It is interesting that Bacillus spp. was isolated in $4 \%$ of the clinical mastitis cases. Other bacteria such as Corynebacterium bovis and Arcanobacterium pyogenes each represented less than $1 \%$ of all cases.

\section{Effect of Clinical Mastitis Treatment Program}

Risk of Receiving Primary Intramammary Antibiotic Therapy Because of Study Assignment. One hundred percent of quarter cases assigned to positive-control treatment received intramammary treatment. The proportion of quarter cases receiving intramammary antibiotic therapy as a consequence of assignment to the culture-based treatment program was $44 \%$ (Table 3). This ranged from 31 to $89 \%$ for the 8 dairy herds enrolled in the study. The etiologic agent classification distribution, based on on-farm cul- ture for the $56 \%$ of cases assigned to the culture-based treatment group that did not receive intramammary antibiotic therapy, was $27 \%$ no growth and $29 \%$ gramnegative. For the $44 \%$ of the clinical mastitis cases that did receive intramammary antibiotic therapy, it was $39 \%$ gram-positive and 5\% mixed infections. Treatment decisions based on on-farm culture agreed $81 \%$ of the time with those that would be taken if based on laboratory results. Laboratory culture results for cases assigned to the culture-based treatment group that did not receive intramammary antibiotic therapy were $45 \%$ no growth, $40 \%$ gram-negative, $14 \%$ gram-positive, and $1 \%$ mixed infections. Laboratory culture results for clinical mastitis cases that did receive intramammary antibiotic therapy were $19 \%$ no growth, $8 \%$ gramnegative, $69 \%$ gram-positive, and $4 \%$ mixed infections.

Risk of Receiving Secondary Intramammary Antibiotic Therapy Because of Non-Responsive Cases. The risk for a quarter case to receive secondary (or extended) intramammary antibiotic therapy 
Table 3. Risk of receiving primary intramammary antibiotic therapy and risk of receiving primary or secondary intramammary antibiotic therapy for 2 clinical mastitis treatment programs

\begin{tabular}{|c|c|c|c|c|}
\hline \multirow[b]{2}{*}{ Item } & \multicolumn{2}{|c|}{$\begin{array}{l}\text { Risk of receiving primary intramammary } \\
\text { antibiotic therapy }{ }^{1}\left[\%^{2}(\mathrm{n})^{3}\right]\end{array}$} & \multicolumn{2}{|c|}{$\begin{array}{l}\text { Risk of receiving primary or secondary } \\
\text { intramammary antibiotic therapy }{ }^{4}[\%(\mathrm{n})]\end{array}$} \\
\hline & Positive-control & Culture-based & Positive-control & Culture-based \\
\hline $\begin{array}{l}\text { Quarter }^{5} \\
\text { Cow }^{6} \\
\text { Herd range }^{7}\end{array}$ & $\begin{array}{l}100(229) \\
100(214) \\
100\end{array}$ & $\begin{array}{l}44(220) \\
44(208) \\
31-89\end{array}$ & $\begin{array}{l}100(229) \\
100(214) \\
100\end{array}$ & $\begin{array}{l}51(220) \\
51(208) \\
36-100\end{array}$ \\
\hline $\begin{array}{l}{ }^{1} \text { Risk of recei } \\
{ }^{2} \text { The fraction } \\
\text { number of qu } \\
{ }^{3} \mathrm{n} \text { was the de } \\
{ }^{4} \text { Risk of recei } \\
\text { severity asses } \\
{ }^{5} \text { Risk of a qu } \\
{ }^{6} \text { Risk of a cov }\end{array}$ & $\begin{array}{l}\text { g intramammary antil } \\
\text { merator was the num } \\
\text { ers or cows enrolled. } \\
\text { minator of the fraction } \\
\text { g intramammary anti } \\
\text { ent decision after enro } \\
\text { affected with clinica }\end{array}$ & $\begin{array}{l}\text { therapy because o } \\
\text { f quarters or cows } \\
\text { a which percentage } \\
\text { c therapy because } \\
\text { it (secondary). } \\
\text { stitis receiving intr }\end{array}$ & $\begin{array}{l}\text { udy assignment (prin } \\
\text { each category and tl } \\
\text { ere calculated. } \\
\text { study assignment (p } \\
\text { ammary antibiotic th }\end{array}$ & ry) or because of \\
\hline
\end{tabular}

was lower for cases assigned to culture-based treatment than for cases assigned to positive-control treatment [model odds ratio estimate of treatment effect using positive-control as reference $\left(\mathbf{O R}_{\mathbf{P C}} ; 95 \% \mathrm{CI}\right)=0.4$ $(0.3,0.7) ; P=0.002 ;$ Table 4]. This risk was numerically lower in cases assigned to culture-based treatment in 6 of the 8 herds enrolled in the study. No other covariates in addition to the explanatory variable of interest, treatment program, remained in the model because of confounding the treatment program effect on the risk of receiving secondary intramammary antibiotic therapy.

Secondary intramammary antibiotic therapy was administered in $36 \%$ of the cases assigned to the positive-control treatment and in $19 \%$ of the cases assigned to culture-based treatment. In cases assigned to culture-based treatment, secondary therapy was administered in $13 \%$ of the non-treated cases and in $28 \%$ of cases that received intramammary antibiotic therapy at enrollment. The overall risk of receiving secondary intramammary antibiotic therapy for both treatment programs was greater in gram-positive $(30 \%)$ or gramnegative ( $42 \%$ ) cases, as compared with no-growth cases $(11 \%)$. The risk difference for secondary intramammary antibiotic therapy between cases assigned to positivecontrol and culture-based treatments was numerically greater for gram-negative cases $57 \%$ for cases assigned to positive-control treatment vs. $23 \%$ for cases assigned to culture-based treatment) and for no-growth cases (16\% for cases assigned to positive-control treatment vs. $7 \%$ for cases assigned to culture-based treatment) than for gram-positive cases (34\% for cases assigned to positive-control treatment vs. $26 \%$ for cases assigned to culture-based treatment).

Risk of Receiving Intramammary Antibiotics Because of Primary or Secondary Therapy.
The risk for a quarter case to receive intramammary antibiotic therapy because of either study assignment or secondary treatment was half for cases assigned to culture-based treatment group as compared with cases assigned to positive-control treatment. The model relative risk estimate of treatment effect using positive control as reference $\left(\mathrm{RR}_{\mathrm{PC}}\right), 95 \%$ confidence interval, and $P$-value were $0.51,0.44$ to 0.58 , and $P<0.001$, respectively (Table 4). Fifty-one percent of the cases assigned to the culture-based treatment group received antibiotic therapy ( $44 \%$ because of study assignment and $7 \%$ because of secondary treatment of cases not treated initially with antibiotics).

Days to Clinical Cure. No significant difference existed in days to return to visibly normal milk between cows assigned to both treatment programs [positivecontrol hazard ratio $(95 \% \mathrm{CI})=0.8(0.6,1.2) ; P=$ 0.258; Table 4 and Figure 1]. This time was numerically shorter in cases assigned to positive-control treatment in 5 of the 8 herds enrolled in the study. The only covariate that remained in the model because of confounding the treatment program effect on days to return to visible normal milk was severity of the clinical mastitis case.

The mean days for milk to return to being visibly normal was $2.7 \mathrm{~d}$ for cases assigned to positive-control treatment and $3.2 \mathrm{~d}$ for cases assigned to culture-based treatment (Table 5). The overall days out of the tank for both clinical mastitis treatment programs for nogrowth, gram-negative, and gram-positive cases were $2.8,3.2$, and $3.1 \mathrm{~d}$, respectively.

Days Out of the Tank. There was a tendency for fewer days of milk withheld from the market for cows with cases assigned to culture-based treatment than for cases assigned to positive-control treatment [positive- 
Table 4. Treatment effects, model fit statistics, and covariance parameters for random and fixed effects of models evaluating different outcomes ${ }^{1}$

\begin{tabular}{|c|c|c|c|c|c|c|c|}
\hline Item & $\begin{array}{l}\text { Risk of receiving } \\
\text { secondary therapy }\end{array}$ & $\begin{array}{c}\text { Risk of receiving } \\
\text { primary or secondary } \\
\text { therapy }^{3}\end{array}$ & $\begin{array}{l}\text { Days to } \\
\text { clinical cure }\end{array}$ & $\begin{array}{l}\text { Days out } \\
\text { of the tank }\end{array}$ & $\begin{array}{l}\text { Bacteriological } \\
\text { cure risk }\end{array}$ & $\begin{array}{l}\text { New IMI } \\
\text { risk }\end{array}$ & $\begin{array}{l}\text { Treatment } \\
\text { failure risk }^{4}\end{array}$ \\
\hline \multicolumn{8}{|l|}{ Treatment effect } \\
\hline $\begin{array}{l}\text { Risk ratio } \\
(95 \% \mathrm{CI})\end{array}$ & $\begin{array}{c}\mathrm{OR}_{\mathrm{PC}}=0.4 \\
(0.3,0.7)\end{array}$ & $\begin{array}{l}\mathrm{RR}_{\mathrm{PC}}=0.5 \\
\quad(0.4,0.6)\end{array}$ & $\begin{array}{r}\mathrm{HR}_{\mathrm{PC}}=0.8 \\
(0.6,1.2)\end{array}$ & $\begin{array}{r}\mathrm{HR}_{\mathrm{PC}}=1.2 \\
\quad(0.9,1.4)\end{array}$ & $\begin{array}{c}\mathrm{OR}_{\mathrm{PC}}=0.6 \\
(0.3,1.4)\end{array}$ & $\begin{array}{c}\mathrm{OR}_{\mathrm{PC}}=1.0 \\
(0.6,1.6)\end{array}$ & $\begin{array}{r}\mathrm{OR}_{\mathrm{PC}}=0.8 \\
(0.5,1.4)\end{array}$ \\
\hline$P$-value & 0.002 & $<0.001$ & 0.258 & 0.079 & 0.204 & 0.942 & 0.541 \\
\hline \multicolumn{8}{|l|}{ Fit statistics } \\
\hline \multicolumn{4}{|l|}{ Covariance parameter [coefficient (SE)] } & & 820 & 1,354 & 1,745 \\
\hline $\begin{array}{l}\text { Herd } \\
\text { (Random effect) }\end{array}$ & $\begin{array}{c}0.371 \\
(0.284)\end{array}$ & $\begin{array}{c}0.662 \\
(0.655)\end{array}$ & - & - & $\begin{array}{c}1.591 \\
(0.858)\end{array}$ & $\begin{array}{c}0.048 \\
(0.073)\end{array}$ & 0 \\
\hline $\begin{array}{l}\text { Cow } \\
\text { (Random effect) }\end{array}$ & $\begin{array}{c}0.506 \\
(0.330)\end{array}$ & $\begin{array}{c}0.295 \\
(0.387)\end{array}$ & - & - & $<0.001$ & $\begin{array}{c}(0.068 \\
(0.311)\end{array}$ & $\begin{array}{c}0.281 \\
(0.380)\end{array}$ \\
\hline Intercept & $\begin{array}{c}-1.419 \\
(0.298)\end{array}$ & $\begin{array}{c}0.390 \\
(0.350)\end{array}$ & - & - & $\begin{array}{r}-0.282 \\
(0.947)\end{array}$ & $\begin{array}{c}-0.194 \\
(0.499)\end{array}$ & $\begin{array}{l}1.265 \\
(0.184)\end{array}$ \\
\hline \multicolumn{8}{|l|}{ Treatment (main effect) } \\
\hline Culture-based & $\begin{array}{l}-0.811 \\
(-0.245)\end{array}$ & $\begin{array}{c}-4.677 \\
(-0.728)\end{array}$ & $\begin{array}{l}-0.214 \\
(-0.189)\end{array}$ & $\begin{array}{c}0.160 \\
(-0.091)\end{array}$ & $\begin{array}{l}-0.536 \\
(-0.356)\end{array}$ & $\begin{array}{c}0.008 \\
(-0.232)\end{array}$ & $\begin{array}{c}-0.160 \\
(0.263)\end{array}$ \\
\hline Positive-control & Reference & Reference & Reference & Reference & Reference & Reference & Reference \\
\hline \multicolumn{8}{|l|}{ No. of quarters affected (covariate) } \\
\hline 1 & - & - & - & $\begin{array}{c}0.372 \\
(0.268)\end{array}$ & - & $\begin{array}{c}0.239 \\
(0.458)\end{array}$ & - \\
\hline \multicolumn{8}{|l|}{$\begin{array}{l}2+ \\
\text { Severity (covariate) }\end{array}$} \\
\hline Mild & - & - & $\begin{array}{c}0.225 \\
(0.141)\end{array}$ & - & - & - & - \\
\hline \multicolumn{7}{|l|}{ Etiology (covariate) } & - \\
\hline Gram-negatives & - & - & - & $\begin{array}{c}-0.341 \\
(0.118)\end{array}$ & $\begin{array}{l}1.388 \\
(0.870)\end{array}$ & $\begin{array}{c}-0.004 \\
(0.293)\end{array}$ & - \\
\hline Gram-positives & - & - & - & $\begin{array}{c}-0.536 \\
(0.124)\end{array}$ & $\begin{array}{c}0.652 \\
(0.855)\end{array}$ & $\begin{array}{c}0.133 \\
(0.273)\end{array}$ & - \\
\hline Mixed infection contaminated & - & - & - & $\begin{array}{c}-0.415 \\
(0.164)\end{array}$ & Reference & $\begin{array}{c}-0.035 \\
(0.753)\end{array}$ & - \\
\hline No growth & - & - & - & Reference & - & Reference & - \\
\hline
\end{tabular}

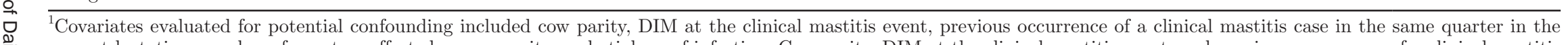
$\stackrel{\varrho}{\aleph}$. present lactation, number of quarters affected, case severity, and etiology of infection. Cow parity, DIM at the clinical mastitis event, and previous occurrence of a clinical mastitis (s) case in the same quarter in the present lactation were not confounders for any of the outcomes evaluated.

$\stackrel{2}{\Phi}$. $\quad{ }^{2}$ Risk of receiving intramammary antibiotic therapy because of study assignment (primary).

Ә ${ }^{3}$ Risk of receiving intramammary antibiotic therapy because of study assignment (primary) or because of a severity assessment decision after enrollment (secondary).

$\lesssim \quad{ }^{4}$ Risk of infection, secondary treatment, clinical mastitis recurrence, or removal from herd within $21 \mathrm{~d}$ after enrollment.

$\quad{ }^{5} \mathrm{OR}_{\mathrm{PC}}=$ model odds ratio estimate of treatment effect using positive-control as reference; $\mathrm{RR}_{\mathrm{PC}}=$ model relative risk estimate of treatment effect using positive control as reference;

$\stackrel{\mathrm{HR}_{\mathrm{PC}}}{\perp}$ model hazard ratio estimate of treatment effect using positive control as reference. 


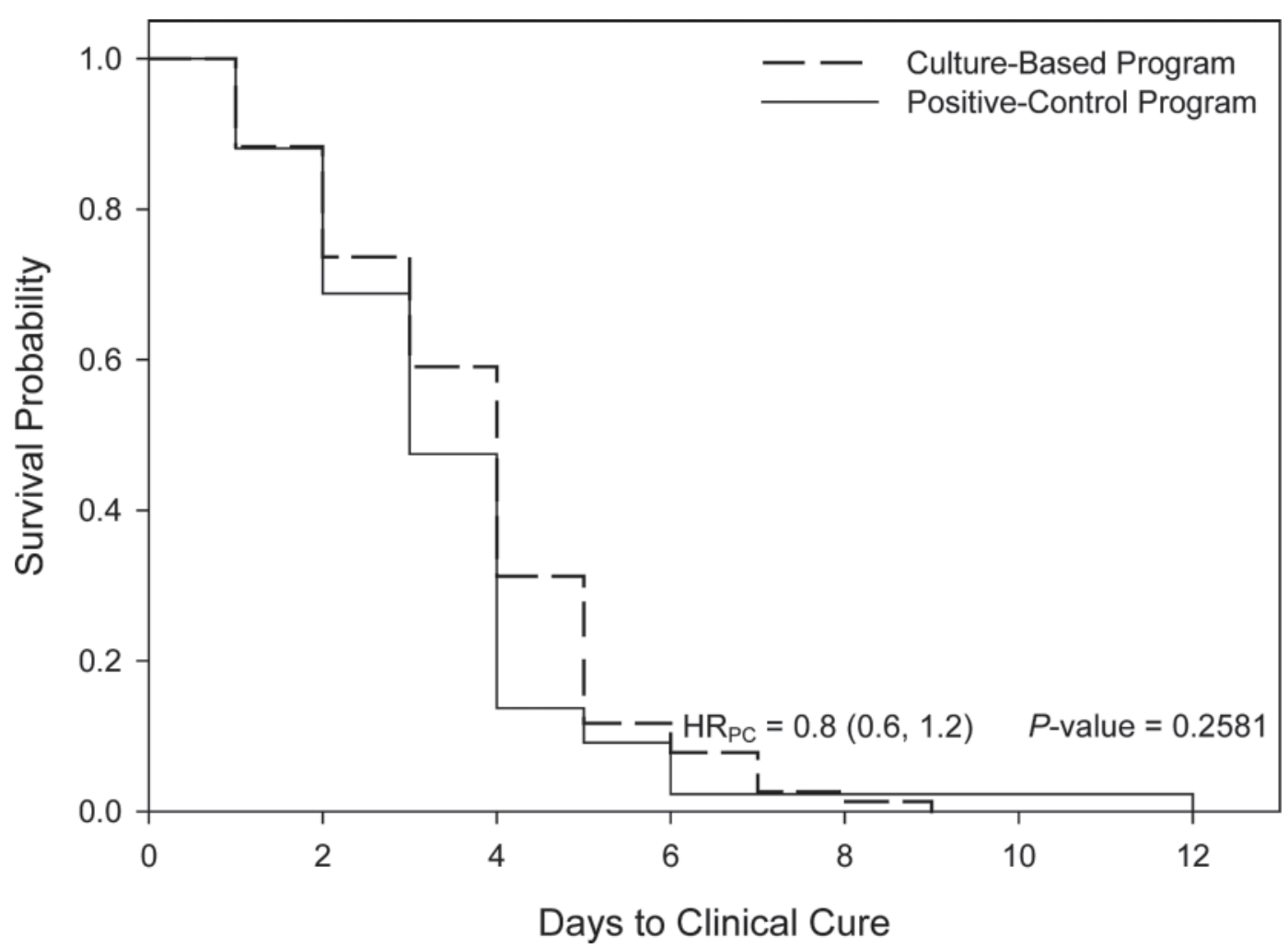

Figure 1. Kaplan-Meier survival graph representing the probability of a clinical cure at a given day after the clinical mastitis event for 2 clinical mastitis treatment programs. $\mathrm{HR}_{\mathrm{PC}}=$ model hazard ratio estimate of treatment effect using positive control as reference.

control hazard ratio $(95 \% \mathrm{CI})=1.2(0.9,1.4) ; P=$ 0.080; Table 4 and Figure 2]. This time was numerically shorter in cases assigned to culture-based treatment in 5 of the 8 herds enrolled in the study. Covariates that remained in the model because of confounding the treatment program effect on days of milk withheld from the market were number of quarters affected and etiology of infection.

The average days of milk withheld from the market was $5.9 \mathrm{~d}$ for cases assigned to positive-control treatment and $5.2 \mathrm{~d}$ for cases assigned to culture-based treatment (Table 5). The difference in days of milk withheld from the market between positive-control and culture-based treatment was much greater for gram-negative cases $(6.2$ vs. $4.9 \mathrm{~d})$, or no-growth cases ( 5.5 vs. $3.9 \mathrm{~d})$, than for gram-positive cases (6.1 vs. $6.5 \mathrm{~d}$ ).

Bacteriological Cure Risk. No significant difference existed in risk for a bacteriological cure between the 2 treatment programs $\left[\mathrm{OR}_{\mathrm{PC}}(95 \% \mathrm{CI})=0.6(0.3\right.$, $1.4) ; P=0.204$; Table 4]. The only covariate that remained in the model because of confounding the treatment program effect on bacteriological cure risk was etiology of infection.

Table 5. Days to clinical cure and days out of the tank for 2 clinical mastitis treatment programs

\begin{tabular}{lcclcc}
\hline & \multicolumn{2}{c}{ Days to clinical cure $\left[\right.$ mean $\left.\pm \mathrm{SD}(\mathrm{n})^{2}\right]$} & & \multicolumn{2}{c}{ Days out of the tank $[\mathrm{mean} \pm \mathrm{SD}(\mathrm{n})]$} \\
\cline { 2 - 3 } \cline { 5 - 6 } Etiology $^{1}$ & Positive-control & Culture-based & & Positive-control & Culture-based \\
\hline No growth & $2.7 \pm 1.3(61)$ & $3.0 \pm 1.7(51)$ & & $5.5 \pm 2.6(63)$ & $3.9 \pm 3.1(58)$ \\
Gram-negatives & $3.1 \pm 2.0(57)$ & $3.4 \pm 1.5(39)$ & & $6.2 \pm 2.5(58)$ & $4.9 \pm 2.7(41)$ \\
Gram-positives & $2.6 \pm 1.1(54)$ & $3.5 \pm 1.6(62)$ & & $6.1 \pm 3.6(62)$ & $6.5 \pm 3.7(72)$ \\
All cases $^{3}$ & $2.7 \pm 1.5(196)$ & $3.2 \pm 1.7(163)$ & & $5.9 \pm 2.9(183)$ & $5.2 \pm 3.5(184)$ \\
Herd range $^{3}$ & $2.2-3.5$ & $2.6-3.8$ & & $5.0-6.3$ & $3.6-8.3$ \\
\hline
\end{tabular}

${ }^{1}$ Etiological classification was based on laboratory culture results.

${ }^{2} \mathrm{n}$ is the population from which means and standard deviations were calculated.

${ }^{3}$ Herd range for the different descriptors [minimum herd (\%)-maximum herd (\%)]. 


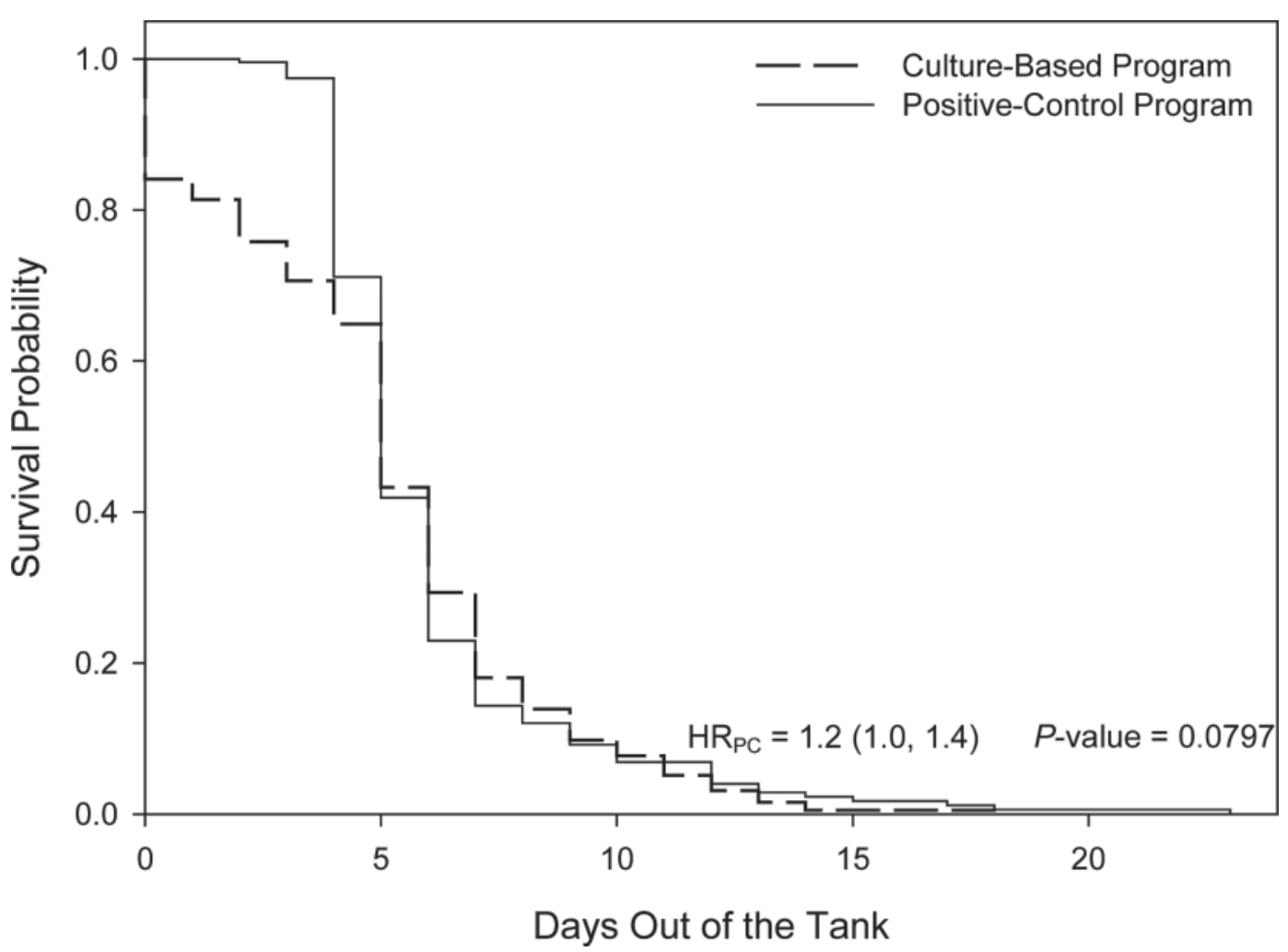

Figure 2. Kaplan-Meier survival graph representing the probability of milk to return to tank at a given day after the clinical mastitis event for 2 clinical mastitis treatment programs. $\mathrm{HR}_{\mathrm{PC}}=$ model hazard ratio estimate of treatment effect using positive control as reference.

The proportion of quarters with bacteriological cure was 71 and $60 \%$ for cases assigned to positive-control and to culture-based treatment, respectively (Table 6). The overall bacteriological cure risk for both clinical mastitis treatment programs for gram-negative and gram-positive cases was 78 and $55 \%$, respectively.
New IMI Risk. No significant difference existed in risk for new IMI between treatment programs $\left[\mathrm{OR}_{\mathrm{PC}}\right.$ $(95 \%$ CI $)=1.0(0.6,1.6) ; P=0.942$; Table 4]. Covariates that remained in the model because of confounding the treatment program effect on new IMI risk included number of quarters affected and etiology of infection.

Table 6. Quarter-level bacteriological cure risk, new IMI risk, infection risk at 14 or 21 d after enrollment, and treatment failure risk (infection risk, secondary treatment, clinical recurrence, or removal from herd) within $21 \mathrm{~d}$ after enrollment for 2 clinical mastitis treatment programs

\begin{tabular}{|c|c|c|c|c|c|c|c|c|}
\hline \multirow[b]{2}{*}{ Etiology ${ }^{1}$} & \multicolumn{2}{|c|}{$\begin{array}{l}\text { Bacteriological } \\
\text { cure risk }\end{array}$} & \multicolumn{2}{|c|}{$\begin{array}{c}\text { New IMI risk } \\
{\left[\%^{2}(\mathrm{n})^{3}\right]}\end{array}$} & \multicolumn{2}{|c|}{$\begin{array}{l}\text { Infection risk } \\
(14 \text { or } 21 \mathrm{~d})\end{array}$} & \multicolumn{2}{|c|}{$\begin{array}{l}\text { Treatment failure risk } \\
\text { (within } 21 \mathrm{~d} \text { ) }\end{array}$} \\
\hline & $\begin{array}{l}\text { Positive- } \\
\text { control }\end{array}$ & $\begin{array}{l}\text { Culture- } \\
\text { based }\end{array}$ & $\begin{array}{l}\text { Positive- } \\
\text { control }\end{array}$ & $\begin{array}{l}\text { Culture- } \\
\text { based }\end{array}$ & $\begin{array}{l}\text { Positive- } \\
\text { control }\end{array}$ & $\begin{array}{l}\text { Culture- } \\
\text { based }\end{array}$ & $\begin{array}{l}\text { Positive- } \\
\text { control }\end{array}$ & $\begin{array}{l}\text { Culture- } \\
\text { based }\end{array}$ \\
\hline No growth & - & - & $50(54)$ & $53(62)$ & $50(54)$ & $53(62)$ & $64(59)$ & $64(66)$ \\
\hline Gram-negatives & $86(42)$ & $70(37)$ & $52(44)$ & $49(41)$ & $63(43)$ & $68(41)$ & $89(57)$ & $83(41)$ \\
\hline Escherichia coli & $83(30)$ & $78(22)$ & $43(30)$ & $41(22)$ & $58(26)$ & $57(30)$ & $90(42)$ & $77(26)$ \\
\hline Klebsiella spp. & $86(7)$ & $62(13)$ & $43(7)$ & $55(11)$ & $85(13)$ & $63(8)$ & $78(9)$ & $92(13)$ \\
\hline Gram-positives & $59(46)$ & $52(48)$ & $54(54)$ & $55(56)$ & $77(56)$ & $79(62)$ & $84(64)$ & $90(71)$ \\
\hline Non-agalactiae streptococci & $57(14)$ & $61(18)$ & $53(19)$ & $63(24)$ & $80(25)$ & $79(19)$ & $82(22)$ & $93(27)$ \\
\hline Staphylococcus spp. & $53(15)$ & $54(13)$ & $55(11)$ & $40(10)$ & $67(12)$ & $73(11)$ & $81(16)$ & $79(19)$ \\
\hline Staphylococcus aureus & $43(7)$ & $18(11)$ & $14(7)$ & $22(9)$ & $82(11)$ & $78(9)$ & $83(12)$ & $93(15)$ \\
\hline Bacillus spp. & $71(7)$ & $75(4)$ & $50(6)$ & $33(3)$ & $80(5)$ & $75(8)$ & $100(10)$ & $100(5)$ \\
\hline All cases & $71(97)$ & $60(85)$ & $50(163)$ & $50(160)$ & $62(165)$ & $65(168)$ & $81(200)$ & $78(181)$ \\
\hline
\end{tabular}

${ }^{1}$ Etiological classification was based on laboratory culture results.

${ }^{2}$ The fraction numerator was the number of quarters experiencing the outcome of interest and the denominator was the number of quarters in each category.

${ }^{3} \mathrm{n}$ is the denominator of the fraction from which the percentage was calculated. 
The proportion of quarters with a new IMI was $50 \%$ for cases assigned to both clinical mastitis treatment programs (Table 6). The overall risk for new IMI for both clinical mastitis treatment programs for nogrowth, gram-negative, and gram-positive cases was 52 , 51 , and $55 \%$, respectively.

Treatment Failure Risk. No significant differences existed in the treatment failure risk (represents the presence of infection risk, secondary treatment, clinical mastitis recurrence risk, or removal from herd risk within $21 \mathrm{~d}$ after enrollment) between both treatment programs $\left[\mathrm{OR}_{\mathrm{PC}}(95 \% \mathrm{CI})=0.8(0.5,1.4) ; P=0.541\right.$; Table 4]. No other covariates in addition to the explanatory variable of interest, treatment program, remained in the model because of confounding the treatment program effect on the treatment failure risk.

The treatment failure risk was 81 and $78 \%$ for cases assigned to positive-control and to culture-based treatment, respectively (Table 6). The partial contribution to the overall $79 \%$ treatment failure risk for both clinical mastitis treatment programs was $63 \%$ for the infection risk at 14 or $21 \mathrm{~d}$ after enrollment, $12 \%$ for the secondary treatment, $3 \%$ for the clinical mastitis recurrence risk, and $1 \%$ for the culling or death risk during this time. The treatment failure risk for no-growth, gramnegative, and gram-positive cases was 64,87 , and $87 \%$, respectively (Table 6).

\section{Power Analysis}

The current study sample size provided an excess of $95 \%$ confidence and $80 \%$ power to detect a difference in (1) secondary intramammary antibiotic therapy of $12 \%$ or greater, (2) days to clinical cure of $1 \mathrm{~d}$ or more, (3) days out of the tank of $1.6 \mathrm{~d}$ or more, (4) bacteriological cure risk of $17 \%$ or greater, (5) new IMI risk of $16 \%$ or greater, and (6) treatment failure risk of $13 \%$ or greater.

\section{DISCUSSION}

In this study no-growth and gram-negative bacteria culture results represented 34 and $26 \%$ of all clinical mastitis cases, respectively. It has been previously reported that a shift toward environmental pathogens as the major causes of clinical mastitis in the United States, Canada, and several European Countries (Green and Bradley, 1998). In the North American Great Lakes region coliforms were recognized as a major etiology of clinical mastitis 10 and $20 \mathrm{yr}$ ago (Erskine et al., 1988; Sargeant et al., 1998). However, recently, no-growth cases have become the most common culture result, as was found in the current and other studies (Wilson et al., 2004; Olde Riekerink et al., 2007).
Roberson (2003) estimated that antibiotics labeled for intramammary use would not be justified for 50 to $80 \%$ of clinical mastitis cases. The $80 \%$ estimate was based on the assumption that coliform infections and cases where bacteria were not isolated did not benefit from intramammary antibiotic therapy. In the current study, no-growth and gram-negative cases accounted for $60 \%$ of all cases. The use of the bi-plate Minnesota Easy Culture System allowed herd personnel to identify these cases and make a cow-side treatment decision the day after detection of the clinical mastitis case. As a result, only $44 \%$ of the cases assigned to culture-based treatment received intramammary antibiotic therapy as the initial treatment decision. However, because of secondary treatment decisions, the final intramammary antibiotic treatment risk for the culture-based treatment program was $51 \%$.

The higher secondary treatment risk experienced by cases assigned to positive-control treatment, where all clinical mastitis cases were treated initially with antibiotics, may be explained in part by the possibility that herd personnel were more prone to continue antibiotic treatment, once already started, than for cases assigned to culture-based treatment where more than half of the cases were not treated initially. In cases assigned to culture-based treatment, secondary therapy was administered in $28 \%$ of cases that already received intramammary antibiotic therapy because they were identified on-farm as gram-positive or mixed infections. Similarly, secondary treatment was administered in $34 \%$ of cases assigned to positive-control treatment where gram-positive bacteria were isolated. Conversely, in cases assigned to culture-based treatment, secondary therapy was administered in only $13 \%$ of cases that did not receive intramammary antibiotic therapy at enrollment because they were identified as no-growth or gram-negative by on-farm culture. The secondary treatment risk for no-growth and gram-negative bacteria in cases assigned to positive-control treatment was $35 \%$. Other explanations for the greater secondary treatment risk experienced by cases assigned to positive-control treatment could be the risk for contamination when infusing the antibiotic via the teat canal (Erskine et al., 2003), and possible irritation of the mammary tissue caused by the preparation. In addition, some earlier in vitro studies showed that antimicrobials may disturb phagocytosis when given intramammary (Ziv et al., 1983; Nickerson et al., 1986), but the clinical relevance of this finding is unknown.

Problems attributed to the use of antibiotics in foodproducing animals include those of increased risk of antibiotic residue violations and the potential for development of antibiotic resistance. Different reports found that the majority of residue violations are related to the 
antibacterial therapy of mastitis, accounting for 82 and $90 \%$ of the inhibitory residue occurrences, respectively (Reneau, 1993; Erskine et al., 2003). Furthermore, it has been established that the risk of an antimicrobial residue violation is associated with the frequency of intramammary antibiotic use on farm, and so also associated with the number of clinical mastitis cases treated with antibiotics. Farmers with an antimicrobial residue violation reported 2.01 cows treated with antibiotics per month, whereas residue-free farmers reported 1.28 cows treated per month (McEwen et al., 1991). It is expected that the on-farm culture-associated decrease in antibiotic use for the selective treatment of clinical mastitis will result in decreased antibiotic use and a decrease in the potential of antimicrobial residue occurrences. Milk processors test incoming milk for antibiotic residues and dairy farmers pay severe penalties when found to be in violation; therefore, this risk-avoidance strategy would add to the on-farm savings derived from a decrease in antibiotic use.

Appropriate use of antibiotic use in animals is a concern among animal health care providers. The Center for Veterinary Medicine of the Food and Drug Administration (FDA), in cooperation with the American Veterinary Medical Association (AVMA), compiled 15 general principles for the judicious use of antimicrobials for dairy cattle veterinarians (FDA-Center for Veterinary Medicine, 2008). These principles emphasize the use of culture to aid in the selection of antimicrobials, confine the use of antimicrobials to appropriate clinical indications, and limit therapeutic antimicrobial treatment to the fewest animals indicated. The selective treatment of clinical mastitis based on on-farm culture results implements those principles by decreasing antibiotic use by half without a decrease in treatment efficacy. If $50 \%$ of all antimicrobial drugs used in dairy farms are dedicated to clinical mastitis treatment (Pol and Ruegg, 2007), the selective treatment of clinical mastitis based on on-farm culture results has the potential to decrease total antibiotic use on dairy farms by $25 \%$.

Discarded milk following treatment can exceed $\$ 100$ per cow in the herd per year (Bartlett et al., 1991). In the present study, a tendency existed for fewer days of milk withheld from the market for cases assigned to culture-based treatment than for cases assigned to positive-control treatment. Milk from all cows assigned to positive-control treatment required at least a 96-h milkwithdraw period because of intramammary antibiotic treatment, whereas only $51 \%$ of the cows assigned to culture-based treatment were treated with antibiotics because of primary or secondary therapy. In addition, milk from all 4 quarters was never discarded in $13 \%$ of the cases assigned to the culture-based treatment that were not treated with antibiotics due to quarter milking the affected quarter in 2 of the 8 herds. Conversely, treatment was delayed $1 \mathrm{~d}$ in cases assigned to the culture-based treatment that were treated with antibiotics. The result was a tendency for an almost 1-d decrease in days out of the tank for the milk from cows assigned to the culture-based treatment. The availability of more rapid bacteria identification methods could decrease even further the amount of discarded milk. In previous studies the expected decrease in discarded milk in a non-antibiotic treatment regimen has not always been reported. A clinical trial evaluating 2 antibiotic treatment regimens and 1 based just on the administration of oxytocin found that the cost of treatment, calculated by adding the cost of the therapy to the value of the milk withheld, did not differ between 1 of the antibiotic treatments and the non-antibiotic regimen (Van Eenennaam et al., 1995). However, the authors acknowledged that the milk withhold costs for the cows in the oxytocin group included milkings during which cows were producing grossly normal milk following their recovery from mastitis, but those cows still remained in the hospital group to allow sample collection along with their contemporary antibiotic treatment group.

No significant differences existed in days to clinical cure between the clinical mastitis treatment programs. Results from previous studies are contradictory. In a clinical trial, when comparing clinical cure risk between antimicrobial and no antimicrobial clinical mastitis treatments, days to clinical cure did not differ for mild clinical mastitis cases where no bacteria (no growth), streptococci, or coliforms were isolated (Guterbock et al., 1993). Similarly, a study where cows were experimentally infected with $E$. coli and developed moderate and severe clinical mastitis, found no differences in days to clinical cure between antimicrobial and no antimicrobial clinical mastitis treatments (Leininger et al., 2003). Conversely, another study reported that when clinical mastitis was caused by Streptococcus spp. or coliform bacteria, the clinical cure risk by the tenth milking was significantly greater if antibiotics were used (Morin et al., 1998). The present study compares 2 different clinical mastitis treatment programs, not just antimicrobial and no antimicrobial treatment of clinical mastitis. Nevertheless, the clinical cure risk was not different for no-growth or gram-negative cases when they were assigned to the positive-control group, which included antibiotic treatment, versus those cases assigned to the culture-based treatment group, which did not include antibiotic treatment. The duration of clinical signs in the present study (mean, $3.0 \mathrm{~d}$ ) was shorter than that reported in previous studies (5.4 and $4.1 \mathrm{~d}$; Constable and Morin, 2002; Hoe and Ruegg, 2005). This difference may be attributable to the omission of severe cases 
of mastitis in the present study, although differences in clinical cure or clinical mastitis case definition, cow and herd factors, as well as milker or owner awareness of prudent antibiotic usage may also explain the differences in duration of the clinical signs.

The bacteriological cure risk was not different between clinical mastitis treatment programs. Cases where coliforms were isolated had the greatest bacteriological cure, closely followed by Bacillus spp. A similar bacteriological cure risk existed for cases where non-agalactiae streptococci and CNS were isolated. As expected, the lowest bacteriological cure was observed for Staph. aureus cases. A large numerical difference existed in the risk of a bacteriological cure between both clinical mastitis treatment programs for cases where Staph. aureus was isolated (43 vs. 18\%). This difference could be due to chance (i.e., small number of quarters represented), to the 1-d delay in initiating intramammary antibiotic treatment, or due to a failure of the on-farm culture to identify these infections. The latter reason can be discounted, as all cases assigned to culture-based treatment where Staph. aureus was isolated in the laboratory were identified as gram-positive and treated with antibiotics on-farm. It is not possible to discern between the 2 first hypotheses provided. However, given the fact that these cure risks are based on only 7 and 11 cases of clinical mastitis, respectively, it is very possible that these cure risk differences may be numerically different due to chance alone, and so these results should be interpreted with caution.

The infection risk and etiology of infection at 14 and $21 \mathrm{~d}$ after enrollment did not differ statistically between treatment groups. The infection risk at 14 and $21 \mathrm{~d}$ after enrollment may be a better outcome measure of both program treatment decisions than bacteriological cure risk because it represents both the bacteriological cure risk and new infection risk immediately after the clinical mastitis event, and includes in the analysis those clinical mastitis cases in which bacteria were not isolated from the enrollment sample (34\% of the cases). Thus, it may more truly reflect the success of the intervention in the quarter infection status. The inclusion in the calculation of the treatment failure risk of the clinical mastitis recurrence and removal from the herd risks within $21 \mathrm{~d}$ after the clinical mastitis case was also done in an attempt to decrease potential omission bias of cases without a follow-up culture result because of any of those events. In addition, the treatment failure risk outcome eliminates the potential confounding induced by secondary treatments or treatment of recurrent cases of clinical mastitis. Using the treatment failure risk as a dependent variable, no differences were found between the clinical mastitis treatment groups for the combined risk of those outcomes within $21 \mathrm{~d}$ after enrollment.

The omission of clinical mastitis cases where bacteria were not isolated from the enrollment sample (34\% of the cases in the present study) in the bacteriological analysis could introduce selection bias due to omission of data from the analysis. In a clinical trial where treatment groups were balanced by randomization in the etiologic distribution of clinical mastitis, the quarter bacteriological status treatment effect still could be biased if the rate of new infections for cases where bacteria were not isolated differs between treatment groups. This could conceivably happen if 1 of the treatment programs had a protective effect or else introduced new infections in cases where bacteria were not isolated in the enrollment sample. It is our recommendation that future studies evaluating the efficacy of mastitis treatment programs should evaluate the treatment effect in quarter infection status during the follow-up milk sampling on cases where bacteria is not isolated. If, instead of evaluating the efficacy of a treatment program, the objective of the clinical trial is to evaluate the efficacy of an antimicrobial drug for the treatment of clinical mastitis, then the interest of the effect of treatment on bacteriological cure may be restricted to cases where bacteria are isolated before the application of antibiotic treatment (Schukken and Deluyker, 1995). Selection bias in cases without a follow-up culture result because of clinical mastitis recurrence or because the cow was removed from the herd may occur if a differential loss of follow-up occurs between treatment groups. Those losses could be due to differential management of cases assigned to the different groups or truly due to a treatment effect.

This study compared 2 clinical mastitis treatment programs that differed not just on the selective versus comprehensive usages of intramammary antibiotic for treatment of clinical mastitis. The success of the culture-based treatment program also depends on the accuracy of the on-farm culture system and the effects of a 1-d delay to initiate intramammary antibiotic therapy in those quarters selected for treatment. Previous field trials and trials with experimentally induced coliform mastitis have already reported on the inefficacy of antimicrobial treatment (Guterbock et al., 1993; Hallberg et al., 1994; Van Eenennaam et al., 1995; Leininger et al., 2003; Roberson et al., 2004). In addition, it had been reported that treatment of mild or moderate clinical mastitis cases can be postponed for $1 \mathrm{~d}$ with minimal adverse effects, while producers wait for onfarm culture results (Wagner et al., 2007). The present study is the first to evaluate a clinical mastitis selective treatment decision based on on-farm culture, made the 
next day after the clinical mastitis event. Therefore, the strengths of this study are related to the validation of a program to treat clinical mastitis.

One potential limitation of this study is that the label of intramammary antibiotic administered in this study, Cefa-Lak (Fort Dodge Animal Health Inc.) does not include efficacy claims against gram-negative bacteria. Two intramammary antibiotic preparations, one containing hetacillin potassium equivalent to $62.5 \mathrm{mg}$ of ampicillin activity (Hetacin-K; Boehringer Ingelheim USA, Ridgefield, CT) and the other containing $125 \mathrm{mg}$ of ceftiofur (Spectramast LC; Pfizer Animal Health Inc., New York, NY), are currently approved in the United States with a label that claims efficacy against clinical mastitis in lactating dairy cattle associated with E. coli. However, published peer-reviewed studies are lacking that report the efficacy of these 2 antimicrobial formulations to treat clinical mastitis in cases where E. coli or other gram-negative pathogens are isolated. A need exists for controlled field trials evaluating their efficacy in treating clinical mastitis. Furthermore, clinical mastitis-selective treatment programs based on on-farm culture results using these intramammary antibiotic preparations should be evaluated. Until this scientific knowledge becomes available, the validity of the present study results when using antibiotics other than cephapirin sodium is not known.

\section{CONCLUSIONS}

The use of an on-farm culture system to guide the strategic treatment of clinical mastitis decreased intramammary antibiotic use by half and tended to decrease withholding time by $1 \mathrm{~d}$, without significant differences in days to clinical cure, bacteriological cure risk, and new infection risk or treatment failure risk within $21 \mathrm{~d}$ after the clinical mastitis event. Results of this study, in addition to long-term outcomes (Lago et al., 2011), will be used to evaluate the overall cost-benefit of using an on-farm culture system to guide strategic treatment decisions in cows with mild and moderate clinical mastitis.

\section{ACKNOWLEDGMENTS}

The authors thank Daniel Hagman, Grant Williams, Joseph Hochhalter, Krista Steffenhagen, Mackenzie Jones, Margaret Perala, Maya Kuratomi, and Megan Becker for the project implementation work and the Udder Health Laboratory Staff at the University of Minnesota, College of Veterinary Medicine (Saint Paul); Danielle Davignon, Carlo Spanu, Dhananjay Apparao, José Pantoja, Leane Oliveira, and Martín Pol for the project implementation work and Carol Hulland for the laboratory work at the University of Wisconsin, Dairy Science Department; and Amy Stanton, Cindy Todd, Erin Vernooy, and Nicole Perkins for the project implementation work and Anna Bashiri for the laboratory work at the University of Guelph, Ontario Veterinary College (Canada). We also recognize the input provided by John Fetrow (University of Minnesota, College of Veterinary Medicine, Saint Paul), Michael Oakes (University of Minnesota, School of Public Health, Minneapolis), Paul Rapnicki (University of Minnesota, College of Veterinary Medicine), and Steven Stewart (University of Minnesota, College of Veterinary Medicine). A special thanks to the dairy owners and farm personnel for providing their herd and labor for this project. The study was possible thanks to funding provided by the Minnesota Agriculture Experimental Station, Fort Dodge Animal Health Inc. (Fort Dodge, IA), and Dairy Farmers of Ontario. In particular, the authors remember Jon Rosenberg, of Fort Dodge Animal Health Inc., who was especially supportive of this study.

\section{REFERENCES}

Bartlett, P. C., G. Y. Miller, S. E. Lance, and L. E. Heider. 1991. Use of bulk tank and milk filter cultures in screening for Streptococcus agalactiae and coagulase-positive staphylococci. J. Food Prot. 54:848-851.

Barton, M. D. 2000. Antibiotic use in animal feed and its impact on human health. Nutr. Res. Rev. 13:279-299.

Beatty, B., R. Farnsworth, A. Lund, R. Lyon, and G. Ward. 1985. Medium to culture and differentiate coagulase-positive and -negative staphylococci from bovine milk. J. Food Prot. 48:1019-1021.

Constable, P. D., and D. E. Morin. 2002. Use of antimicrobial susceptibility testing of bacterial pathogens isolated from the milk of dairy cows with clinical mastitis to predict response to treatment with cephapirin and oxytetracycline. J. Am. Vet. Med. Assoc. 221:103-108.

Erskine, R. J., R. J. Eberhart, L. J. Hutchinson, S. B. Spencer, and M. A. Campbell. 1988. Incidence and types of clinical mastitis in dairy herds with high and low somatic cell counts. J. Am. Vet. Med. Assoc. 192:761-765.

Erskine, R. J., S. Wagner, and F. J. DeGraves. 2003. Mastitis therapy and pharmacology. Vet. Clin. North Am. Food Anim. Pract. 19:109-138.

Erskine, R. J., R. D. Walker, C. A. Bolin, P. C. Bartlett, and D. G. White. 2002. Trends in antibacterial susceptibility of mastitis pathogens during a seven-year period. J. Dairy Sci. 85:1111-1118.

Erskine, R. J., R. C. Wilson, M. G. Riddell, J. W. Tyler, H. J. Spears, and B. S. Davis. 1992. Intramammary administration of gentamicin as treatment for experimentally induced Escherichia coli mastitis in cows. Am. J. Vet. Res. 53:375-381.

FDA-Center for Veterinary Medicine. 2008. Judicious use of antimicrobials for dairy cattle veterinarians. Accessed Dec. 11, 2008. http:// www.fda.gov/downloads/AnimalVeterinary/SafetyHealth/AntimicrobialResistance/JudiciousUseofAntimicrobials/UCM095571.pdf.

Green, M. J., and A. J. Bradley. 1998. Coliform mastitis: An evolving problem. Cattle Pract. 6:91-94.

Guterbock, W. M., A. L. Van Eenennaam, R. J. Anderson, I. A. Gardner, J. S. Cullor, and C. A. Holmberg. 1993. Efficacy of intramammary antibiotic therapy for treatment of clinical mastitis caused by environmental pathogens. J. Dairy Sci. 76:3437-3444.

Hallberg, J. W., C. L. Henke, and C. C. Miller. 1994. Intramammary antibiotic therapy: To treat or not to treat? Effects on antibiotic 
therapy on clinical mastitis. Pages 28-39 in Proc. 26th Annu. Mtg. Natl. Mastitis Counc., Orlando, FL. National Mastitis Council, Madison, WI.

Hoe, F. G., and P. L. Ruegg. 2005. Relationship between antimicrobial susceptibility of clinical mastitis pathogens and treatment outcome in cows. J. Am. Vet. Med. Assoc. 227:1461-1468.

Lago, A. 2009. Efficacy of on-farm programs for the diagnosis and selective treatment of clinical and subclinical mastitis in dairy cattle. PhD Dissertation, University of Minnesota, St. Paul.

Lago, A., S. M. Godden, R. Bey, P. L. Ruegg, and K. Leslie. 2011. The selective treatment of clinical mastitis based on on-farm culture results: II. Effects on lactation performance, including clinical mastitis recurrence, somatic cell count, milk production and cow survival. J. Dairy Sci. 94:4457-4467.

Leininger, D. J., J. R. Roberson, F. Elvinger, D. Ward, and M. Akers. 2003. Evaluation of frequent milkout for treatment of cows with experimentally induced Escherichia coli mastitis. J. Am. Vet. Med. Assoc. 222:63-66.

Makovec, J. A., and P. L. Ruegg. 2003. Antimicrobial resistance of bacteria isolated from dairy cow milk samples submitted for bacterial culture: 8,905 samples (1994-2001). J. Am. Vet. Med. Assoc. $222: 1582-1589$.

McEwen, S. A., W. D. Black, and A. H. Meek. 1991. Antibiotic residue prevention methods, farm management, and occurrence of antibiotic residues in milk. J. Dairy Sci. 74:2128-2137.

Mitchell, J. M., M. W. Griffiths, S. A. McEwen, W. B. McNab, and A. J. Yee. 1998. Antimicrobial drug residues in milk and meat: Causes, concerns, prevalence, regulations, tests, and test performance. J. Food Prot. 61:742-756.

Morin, D. E., R. D. Shanks, and G. C. McCoy. 1998. Comparison of antibiotic administration in conjunction with supportive measures versus supportive measures alone for treatment of dairy cows with clinical mastitis. J. Am. Vet. Med. Assoc. 213:676-684.

Nickerson, S. C., M. J. Paape, R. J. Harmon, and G. Ziv. 1986. Mammary leukocyte response to drug therapy. J. Dairy Sci. 69:17331742.

NMC. 1999. Laboratory Handbook on Bovine Mastitis. National Mastitis Council, Madison, WI.

Olde Riekerink, R., H. Barkema, D. Poole, D. Kelton, and D. Scholl. 2007. Risk factors for incidence rate of clinical mastitis in a nationwide study on Canadian dairy farms. Page 204 in Proc. 46th Annu. Mtg. Nat. Mast. Counc., San Antonio, TX. National Mastitis Council, Madison, WI.

Owens, W. E., C. H. Ray, J. L. Watts, and R. R. Yancey. 1997. Comparison of success of antibiotic therapy during lactation and results of antimicrobial susceptibility tests for bovine mastitis. J. Dairy Sci. 80:313-317.

Pitkälä, A., M. Haveri, S. Pyörälä, V. Myllys, and T. Honkanen-Buzalski. 2004. Bovine mastitis in Finland 2001-Prevalence, dis- tribution of bacteria, and antimicrobial resistance. J. Dairy Sci. $87: 2433-2441$

Pol, M., and P. L. Ruegg. 2007. Relationship between antimicrobial drug usage and antimicrobial susceptibility of gram-positive mastitis pathogens. J. Dairy Sci. 90:262-273.

Pyörälä, S., L. Kaartinen, H. Käck, and V. Rainio. 1994. Efficacy of two therapy regimens for treatment of experimentally induced Escherichia coli mastitis in cows. J. Dairy Sci. 77:453-461.

Reneau, J. K. 1993. Clinical mastitis records in production medicine programs. Compend. Cont. Educ. Pract. Vet. 15:497-503.

Roberson, J. R. 2003. Establishing treatment protocols for clinical mastitis. Vet. Clin. North Am. Food Anim. Pract. 19:223-234.

Roberson, J. R., L. D. Warnick, and G. Moore. 2004. Mild to moderate clinical mastitis: Efficacy of intramammary amoxicillin, frequent milk-out, a combined intramammary amoxicillin, and frequent milk-out treatment versus no treatment. J. Dairy Sci. 87:583-592.

Sargeant, J. M., H. M. Scott, K. E. Leslie, M. J. Ireland, and A. Bashiri. 1998. Clinical mastitis in dairy cattle in Ontario: Frequency of occurrence and bacteriological isolates. Can. Vet. J. 39:33-38.

SAS Institute. 2003. User's Guide: Statistics. Version 9.1. SAS Inst. Inc., Cary, NC.

Schukken, Y. H., and H. A. Deluyker. 1995. Design of field trials for the evaluation of antibacterial products for therapy of bovine clinical mastitis. J. Vet. Pharmacol. Ther. 18:274-283.

Sol, J., O. C. Sampimon, H. W. Barkema, and Y. H. Schukken. 2000. Factors associated with cure after therapy of clinical mastitis caused by Staphylococcus aureus. J. Dairy Sci. 83:278-284.

Sundlof, S. F., J. B. Kaneene, and R. Miller. 1995. National survey on veterinarian-initiated drug use in lactating dairy cows. J. Am. Vet. Med. Assoc. 207:347-352.

University of Minnesota Laboratory for Udder Health. 2004. Minnesota Easy Culture System II user's manual. University of Minnesota, Saint Paul.

Van Eenennaam, A. L., I. A. Gardner, J. Holmes, L. Perani, R. J. Anderson, J. S. Cullor, and W. M. Guterbock. 1995. Financial analysis of alternative treatments for clinical mastitis associated with environmental pathogens. J. Dairy Sci. 78:2086-2095.

Wagner, S., R. Erskine, and R. Olde Riekerink. 2007. Outcomes of on-farm culture-based mastitis therapy. Pg. 200-201 in Proc. 46th Annu. Mtg. Natl. Mastitis Counc. San Antonio, TX. National Mastitis Council, Madison, WI.

Wilson, D. J., R. N. González, J. Hertl, H. F. Schulte, G. J. Bennett, Y. H. Schukken, and Y. T. Gröhn. 2004. Effect of clinical mastitis on the lactation curve: A mixed model estimation using daily milk weights. J. Dairy Sci. 87:2073-2084.

Ziv, G., M. J. Paape, and A. M. Dulin. 1983. Influence of antibiotics and intramammary antibiotic products on phagocytosis of Staphylococcus aureus by bovine leukocytes. Am. J. Vet. Res. 44:385-388. 